\title{
A vital dye analysis of the timing and pathways of avian trunk neural crest
} cell migration

\author{
GEORGE N. SERBEDZIJA, MARIANNE BRONNER-FRASER* and SCOTT E. FRASER
}

Developmental Biology Center, University of California, Irvine, Ca. 92717, USA

\section{Summary}

To permit a more detailed analysis of neural crest cell migratory pathways in the chick embryo, neural crest cells were labelled with a nondeleterious membrane intercalating vital dye, DiI. All neural tube cells with endfeet in contact with the lumen, including premigratory neural crest cells, were labelled by pressure injecting a solution of Dil into the lumen of the neural tube. When assayed one to three days later, migrating neural crest cells, motor axons, and ventral root cells were the only cells types external to the neural tube labelled with DiI. During the neural crest cell migratory phase, distinctly labelled cells were found along: (1) a dorsolateral pathway, under the epidermis, as well adjacent to and intercalating through the dermamyotome; and (2) a ventral pathway, through the rostral portion of each sclerotome and around the dorsal aorta as described previously. In contrast to those cells migrating through the sclerotome, labelled cells on the dorsolateral pathway were not segmentally arranged along the rostrocaudal axis. Dil-labelled cells were observed in all truncal neural crest derivatives, including subepidermal presumptive pigment cells, dorsal root ganglia, and sympathetic ganglia. By varying the stage at which the injection was performed, neural crest cell emigration at the level of the wing bud was shown to occur from stage 13 through stage 22 . In addition, neural crest cells were found to populate their derivatives in a ventral-to-dorsal order, with the latest emigrating cells migrating exclusively along the dorsolateral pathway.

Key words: DiI, microinjection, pigment cells, cell migration, neural crest, vital dye.

\section{Introduction}

The neural crest is a population of cells that arises in the dorsal neural tube during neurulation (rev. Horstadius, 1950; Weston, 1970). From this position of origin, neural crest cells migrate extensively to diverse locations and give rise to a number of distinct cell types, ranging from neurons to pigment cells (rev. Weston, 1970; LeDouarin, 1982). For these reasons, the neural crest is a useful system for studying cell movement and differentiation. In the trunk region of avian embryos, neural crest cells are thought to migrate along two primary pathways (Weston, 1963; LeDouarin, 1973): dorsolaterally between the somite and the ectoderm, and ventrally through the rostral half of each somitic sclerotome (Rickmann et al. 1985; Bronner-Fraser, 1986; Fig. 1 top). Following their migration, trunk neural crest cells differentiate into pigment cells, dorsal root and sympathetic ganglion cells, and adrenomedullary cells (LeDouarin, 1982).

Because they travel through mesenchymal regions, neural crest cells are difficult to distinguish from the cells through which they migrate. To overcome this difficulty, cell marking techniques have been employed; marked neural tubes, containing premigratory neural crest cells, are transplanted into chicken hosts from which a similar length of neural tube has been removed. The locations and phenotypes of marked cells offer information on both the destinations and the fates of neural crest cells. By transplanting neural tubes labelled with tritiated thymidine into unlabelled hosts, one can produce intraspecific (i.e. within the same species) chimeras (Weston, 1963; Chibon, 1967); however, dilution of the tritiated thymidine marker by mitotic activity renders this technique useful only for analysis of the early stages of migration. The heritable nature of species-specific nuclear markers avoids the problem of dilution (Harrison, 1935; LeDouarin, 1973; Sadaghiani \& Thiebaud, 1987). However, these markers necessitate grafting tissue between different species, which may introduce host/donor incompatibilities (Bellairs et al. 1981). Despite the utility of these approaches, any transplantation involves microsurgery, which itself may disrupt the microenvironment of the marked cells and hence alter their migratory behavior in unpredictable manners.

The use of monoclonal antibodies that recognize neural crest cells permits analysis of neural crest cell localization without surgical manipulation. The antibodies HNK-1 and NC-1 recognize a carbohydrate 
epitope on several cell surface molecules (Kruse $e t$ al. 1984). During the stages of avian neural crest cell migration, these antibodies recognize neural crest cells, some of their derivatives, as well as some other cell types including the neuronal and satellite cells of the peripheral nervous system. (Vincent \& Thiery, 1984; Tucker et al. 1984). Thus, by examining the distribution of HNK-1 or NC-1 in animals fixed and labelled at different times, the pathways and timetable of neural crest cell migration can be inferred. A drawback is that the epitope recognized by these antibodies is on cells other than neural crest cells, and it is not expressed on all neural crest cells and their derivatives. For example, neural crest-derived melanocytes lack HNK-1 immunoreactivity (Vincent \& Thiery, 1984), and single neural crest cells often give rise to progeny that are a mixture of HNK-1-positive and -negative cells (Baroffio et al. 1988; Bronner-Fraser \& Fraser, 1988).

We have developed a vital dye labelling approach to perform detailed analyses of neural crest cell migration. Because it uniquely labels cells yet involves no grafting, this technique circumvents many of the difficulties inherent in previous methods for identifying neural crest cells. Premigratory neural crest cells are labelled by injecting a solution of the fluorescent carbocyanine dye, DiI (1,1-dioctadecyl-3,3,3',3'-tetramethylindocarbocyanine perchlorate), into the lumen of the neural tube. At the time of our injections, the neural tube is a columnar epithelium whose cells, including the premigratory neural crest cells, extend an endfoot to the lumen. The dye is lipid-soluble and hydrophobic, and, thus, can be incorporated nearly irreversibly into the plasma membranes of the cells it contacts (Sims et al. 1974). DiI does not appear to spread from labelled to unlabelled cells or to have adverse effects on either the survival or the development of neuronal cells (Honig \& Hume, 1986). With further development, neural crest cells are the only cell type to exit the neural tube, other than a few Schwann cells (Weston, 1963; Lunn et al. 1987) and motor axons. Dilution of the label is not a great problem due to the high intensity of DiI fluorescence. Therefore, the technique provides an effective

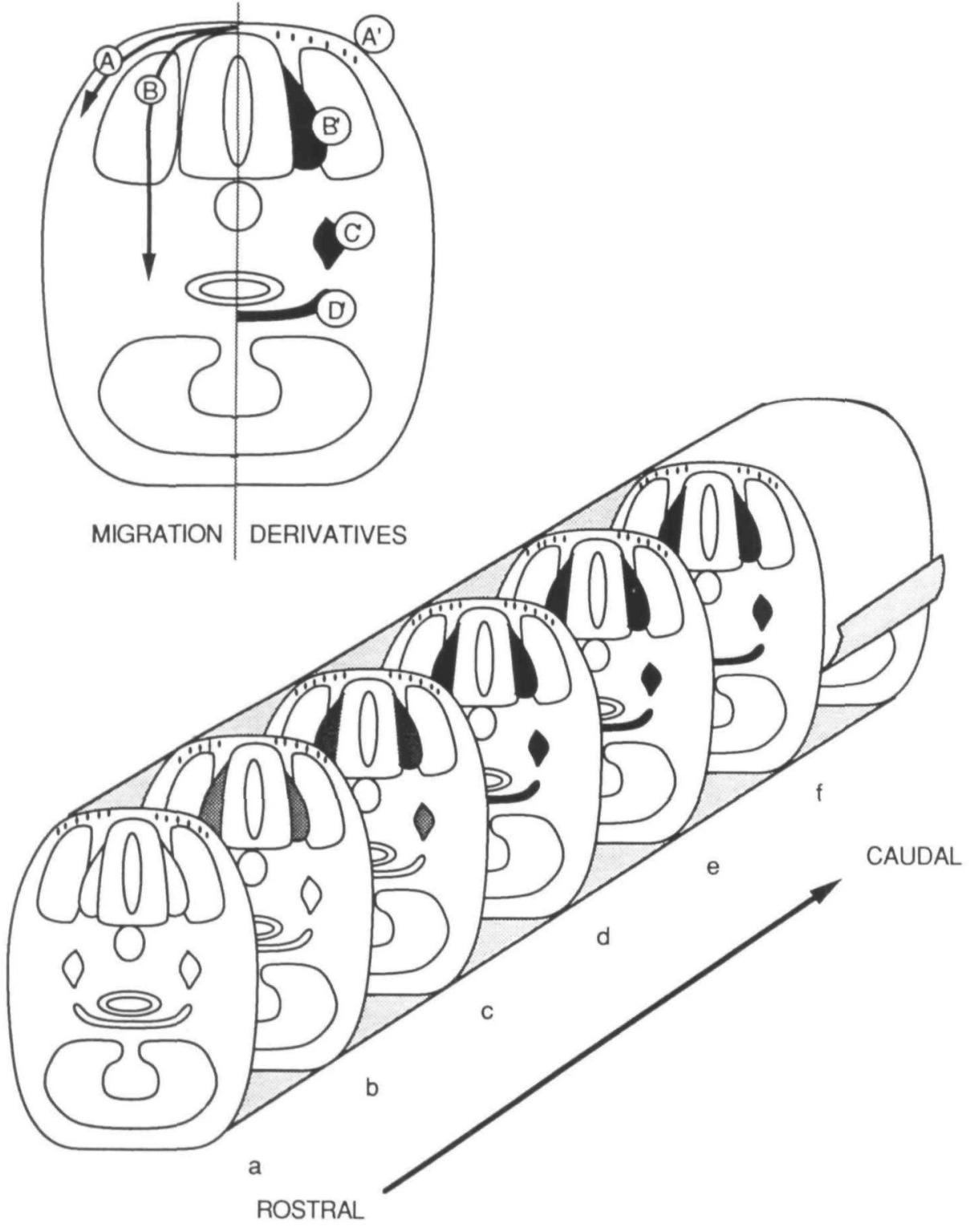

Fig. 1. Top. Trunk neural crest cell migration pathways and derivatives. There are two major pathways: A: the dorsolateral pathway between the somite and the ectoderm, and B: the ventral pathway through the rostral half of each somite. Trunk neural crest give rise to: $\mathrm{A}^{\prime}$, pigment cells; $\mathrm{B}^{\prime}$, dorsal root ganglia; $\mathrm{C}^{\prime}$, sympathetic ganglia; and $\mathrm{D}^{\prime}$, cells around the dorsal aorta. Bottom. A schematic representation of the rostral to caudal distribution of $\mathrm{DiI}$ in the neural crest derivatives of a single embryo injected at stage 19 and fixed at stage 21 . a-f represent levels along the rostrocaudal axis from which transverse sections were taken. a, At the level of the 9 th somite, DiI-labelled cells were observed along the dorsolateral pathway. b, At the level of the 15th somite, DiI-labelled cells were observed along the dorsolateral pathway and in the dorsal root ganglia. $\mathrm{c}$, At the level of the 22nd somite, DiI-labelled cells were seen along the dorsolateral pathway, in the dorsal root ganglia, and in the sympathetic ganglia. d-f, From the level of the 38 th somite to the caudal end of the embryo, Dillabelled cells were observed in all truncal neural crest derivatives. 
method for following the pattern of neural crest cell migration in vivo.

This new intraspecific marking technique has permitted us to confirm and extend previous results from experiments using transplantation and antibody marking methods (c.f. Weston, 1963; LeDouarin, 1982; Rickmann, 1985; Bronner-Fraser, 1986). By controlling the time of DiI injection and postoperative survival time, we have established the duration of neural crest cell emigration from the neural tube and the temporal order in which neural crest cells contribute to their derivatives. Furthermore, we have characterized the migration of presumptive pigment cells along the dorsolateral pathway of the chick.

\section{Materlals and methods}

\section{Preparation of eggs}

White Leghorn chicken embryos were incubated at $37^{\circ} \mathrm{C}$ until they reached stages 12 to 22 (Hamburger \& Hamilton, 1951). The eggs were then washed in $70 \%$ ethanol $(\mathrm{EtOH})$, a window was cut in the shell over the embryo, and India ink (Pelikan, Hanover, FRG) was injected under the blastodisc to aid in visualization of the embryo. The vitelline membrane was removed with a fine tungsten needle to allow access to the embryo. After the injection, the egg was sealed with adhesive tape and returned to the incubator.

\section{Microinjection of dye}

All injections were made with a $0.5 \%$ solution (weight/ volume) in $100 \% \mathrm{EtOH}$ of 1,1-dioctadecyl-3,3,3',3'-tetramethylindocarbocyanine perchlorate (DiI; Molecular Probes, Junction City, OR.). Prior to each use, the dye solution was centrifuged to remove any crystals that might clog the micropipet tip. The micropipet (pulled from thin-walled borosilicate omega-dot capillary tubing) was partially backfilled with the DiI solution and attached to a picospritzer (General Valve). The injection pipet was inserted obliquely into the neural tube (using a hydraulic manipulator; Narashige) at a level two somites rostral to the most recently formed somite. In most cases, $50-70 \mathrm{nl}$ of dye expelled from the pipet spread to fill the entire lumen of the neural tube. In one series of experiments, smaller injection were made at the level of the 17th somite which spread the length of 4-5 somites forward from the injection site.

To determine if the microinjection procedure itself caused disruption to the embryo or the neural crest pathways, stage 17 embryos were injected with $100 \%$ ethanol or saline, incubated for $24 \mathrm{~h}$, sectioned, and stained with HNK-1 antibody as described below. Embryos injected with saline showed no visible signs of damage. In fact, it was generally impossible to identify the injection site. In contrast, embryos injected with ethanol alone showed localized damage to the neural tube at the site of the injection, as might be expected in light of its known toxicity to embryonic cells. At the injection site, the neural tube was split at the dorsal and/or ventral surface, reduced in size and filled with debris. The damage was confined to the neural tube and extended approximately $150 \mu \mathrm{m}$. In regions one somite away from the site of injection, the neural tube appeared unperturbed, and the pattern of HNK-1 staining was the same as that found in uninjected animals. Injections of DiI dissolved in ethanol caused no greater damage; however, the localized damage permitted the epithelial cells of the dermamyotome immediately adjacent to the site of injection to become labelled with DiI. To avoid any confusion, all injections were performed at least 2-somite lengths away from the levels to be analyzed.

\section{Histology}

Embryos ranging from stage 19 to stage 23 were fixed in $4 \%$ paraformaldehyde $/ 0.25 \%$ glutaraldehyde in $0.1 \mathrm{M}$-phosphate buffer (PB) overnight at $4^{\circ} \mathrm{C}$. The glutaraldehyde was added because it fixes lipid membranes better than paraformaldehyde and would thus better preserve the DiI (Longmuir, personal communication). The embryos were prepared for cryostat sectioning by washing in $0.1 \mathrm{M}-\mathrm{PB}$ for $1 \mathrm{~h}$, and by placing them in a $15 \%$ sucrose solution overnight at $4^{\circ} \mathrm{C}$. They were then embedded in $15 \%$ sucrose and $7.5 \%$ gelatin (Sigma), rapidly frozen in liquid nitrogen and serially sectioned on a cryostat (AO Reichert Histostat) at $20 \mu \mathrm{m}$. Sections were mounted on subbed slides, and covered in one drop of $0.1 \mathrm{M}-\mathrm{PB}$, without a coverslip. Coverslips were initially omitted because of the surfactant nature of DiI which caused the dye to spread when it came into contact with the glass coverslip. For later experiments, we discovered that coverslipping the slides with $\mathrm{Gel} /$ mount (Biomedia Corp.) prevented dye spreading and allowed long-term preservation of sections. Slides were viewed immediately on an epifluorescent microscope through a rhodamine filter set to visualize the DiI, and data were recorded photographically.

\section{Immunocytochemistry}

Some sections through Dil-labelled embryos were stained with the monoclonal antibody HNK-1, an IgM that recognizes avian neural crest cells and other cell types (Tucker et al. 1984). Immediately after mounting on subbed slides, the sections were incubated for $1 \mathrm{~h}$ with the HNK-1 antibody. The sections were then rinsed in $0 \cdot 1 \mathrm{M}-\mathrm{PB}$, incubated with a $1: 30$ dilution of rabbit anti-mouse $\operatorname{IgM}$ in $0.1 \%$ bovine serum albumen for $30 \mathrm{~min}$, rinsed again in $0.1 \mathrm{M}-\mathrm{PB}$ and incubated with a 1:30 dilution of FITC goat anti-rabbit IgG in $0.1 \%$ bovine serum albumen for $30 \mathrm{~min}$. After a final rinse, the sections were covered in $0.1 \mathrm{M}-\mathrm{PB}$, and viewed immediately without a coverslip. Sections were viewed with an epifluorescent microscope through a rhodamine filter set for visualizing the DiI and a fluorescein filter set for viewing the HNK-1 antibody labelling.

\section{Results}

These experiments take advantage of the observation that intraluminal injection of DiI labels all the cells of the neural tube whose endfeet are connected to the lumen, including premigratory neural crest cells. In our initial experiments, stage 19 embryos were injected with DiI at the level of the most recently formed somite such that the dye filled the entire neural tube. If fixed and examined immediately, the DiI was found to be restricted to the lumen and the cells of the neural tube. This restriction was present throughout the neuraxis, from rostral levels, where neurogenesis had considerably progressed, to the most caudal levels, where the neural tube is an undifferentiated neuroepithelium (see Fig. 2A).

In embryos injected at stage 19 and incubated until stage 21 , a progressive wave of neural crest migration was observed from the level of somite 8 through to the caudal end of the embryo. In the most rostral sections 
of the trunk that contained label external to the neural tube (approximately somites 8-11), DiI-labelled cells were found only in the ventral root fibers and along the dorsolateral pathway (Fig. 1 bottom, a). Moving caudally, the dorsal root ganglia were the next structures to contain label (Fig. 1 bottom, b). DiI-labelled cells were found only in these three structures for the next several somites (until approximately somite 16). Further caudad, DiI-labelled cells were found in the sympathetic ganglia, in addition to the above three derivatives (Fig. 1 bottom, c). The cells around the dorsal aorta were labelled in only the most caudal portions of the animal. (Fig. 1 bottom, e \& f). The results, summarized in Fig. 1B, suggest an orderly progession of neural crest migration that parallels the rostral to caudal order of neural crest cell emigration from the neural tube. The neural crest cells at the most immature levels appeared to have migrated the furthest ventrally as suggested by Weston (1963).

To analyze in more detail the time-course and the pathways of neural crest cell migration, two sets of cell marking experiments were performed. In the first set of experiments, all neural crest cells were labelled by injecting the dye prior to the onset of migration. Fixation of the animals at progressive times therefore permits an analysis of the progression of neural crest migration. In the second set of experiments, DiI was injected into neural tubes of progressively older embryos, such that only those cells yet to lose their attachment to the lumen of the neural tube will be labelled. This permits an analysis of both the duration of neural crest cell emigration and the order of contribution to neural crest derivatives. To avoid any possible confusion from differences in behavior along the rostrocaudal axis, all analyses were performed at the level of the wing bud, somites 14-16. Table 1 summarizes the number of embryos analyzed for both sets of experiments.

\section{Injections at the onset of neural crest cell migration}

Injections of DiI were made into the neural tube at the midtrunk region of stage 12-14 embryos (16-22 somites), at the level of the most recently formed somite, prior to the onset of neural crest cell migration. Data were collected at least 1-2 somites rostral or caudal to the micropipet entry site, to avoid the region of localized damaged incurred by the injection. Embryos were incubated for 4 to $48 \mathrm{~h}$ prior to fixation, and the distribution of labelled cells determined in transverse and longitudinal sections at the level of the wing bud.

\section{4 hour incubation (stage 13-14)}

In serial transverse sections, the DiI-labelled cells were restricted to the neural tube (Fig. 2A). The border between the DiI-labelled neural tube cells and the nonlabelled cells adjacent to the tube was sharp, indicating that there was no transfer of the dye.

12 hour incubation (stage 17)

In transverse section, DiI-labelled neural crest cells
Table 1. Summary of the number of embryos analyzed

$\begin{array}{lr}\text { Embryos injected at stage 12 } \\ \text { Incubated for } 4 \text { hours } \\ \text { Incubated for } 12 \text { hours } & 17 \\ \text { Incubated for } 24 \text { hours } & 23 \\ \text { Incubated for } 48 \text { hours } & 22 \\ & \\ \text { Embryos injected at progressive } & \\ \text { stages and analyzed at stage 23 } & \\ \text { Injected at stage 12 } & 32 \\ \text { Injected at stage 17 } & 31 \\ \text { Injected at stage 19 } & 35 \\ \text { Injected at stage 21 } & 23 \\ \text { Injected at stage 23 } & 19\end{array}$

Embryos injected at stage 19 and analyzed at stage 21

Embryos double labelled with DiI and HNK-1

Injected at stage 12

Injected at stage 17

Injected at stage 19

23

Control injections

EtOH

Saline

were located between the dorsal surface of the neural tube and the overlying ectoderm in the area between the dorsal midline and the somite (Fig. 2B). In some of the embryos, a few cells could be seen entering the sclerotome. In longitudinal sections, DiI-labelled cells were occasionally observed in the space between the epithelial somites.

\section{4 hour incubation (stage 20-22)}

In transverse sections of stage 20 embryos, DiI-labelled cells extended from the dorsal surface of the neural tube, ventrally to the level of the dorsal aorta as a continuous stream within the sclerotome (Fig. 2C). In longitudinal sections, the streams of DiI-labelled cells were observed within the rostral portion of each somitic sclerotome, but not in the caudal portion (Fig. 2D). Some cells were seen abutting the intersomitic border. It was not clear if these cells were in the intersomitic space or in the rostralmost portion of the sclerotome. In animals analyzed at stage 22 , by which time the dorsal root and sympathetic ganglia have formed (Teillet $e t$ al. 1987; Lallier \& Bronner-Fraser, 1988), cells in both ganglia were labelled with DiI (Fig. 2C).

\section{8 hour incubation (stage 24)}

DiI-labelled cells were found above the dorsal neural tube, in the dorsal root ganglia, the sympathetic ganglia, the ventral root motor axons, and around the dorsal aorta (Fig. 3A). In addition, one to ten DiIlabelled cells per section were found abutting either the ventral or dorsal surface of the dermamyotome, and within the dermamyotome, as well as between the dermamyotome and the ectoderm (Fig. 3A). These dorsally positioned DiI-labelled cells were found either singly or in small clusters. In contrast to the neural crest 

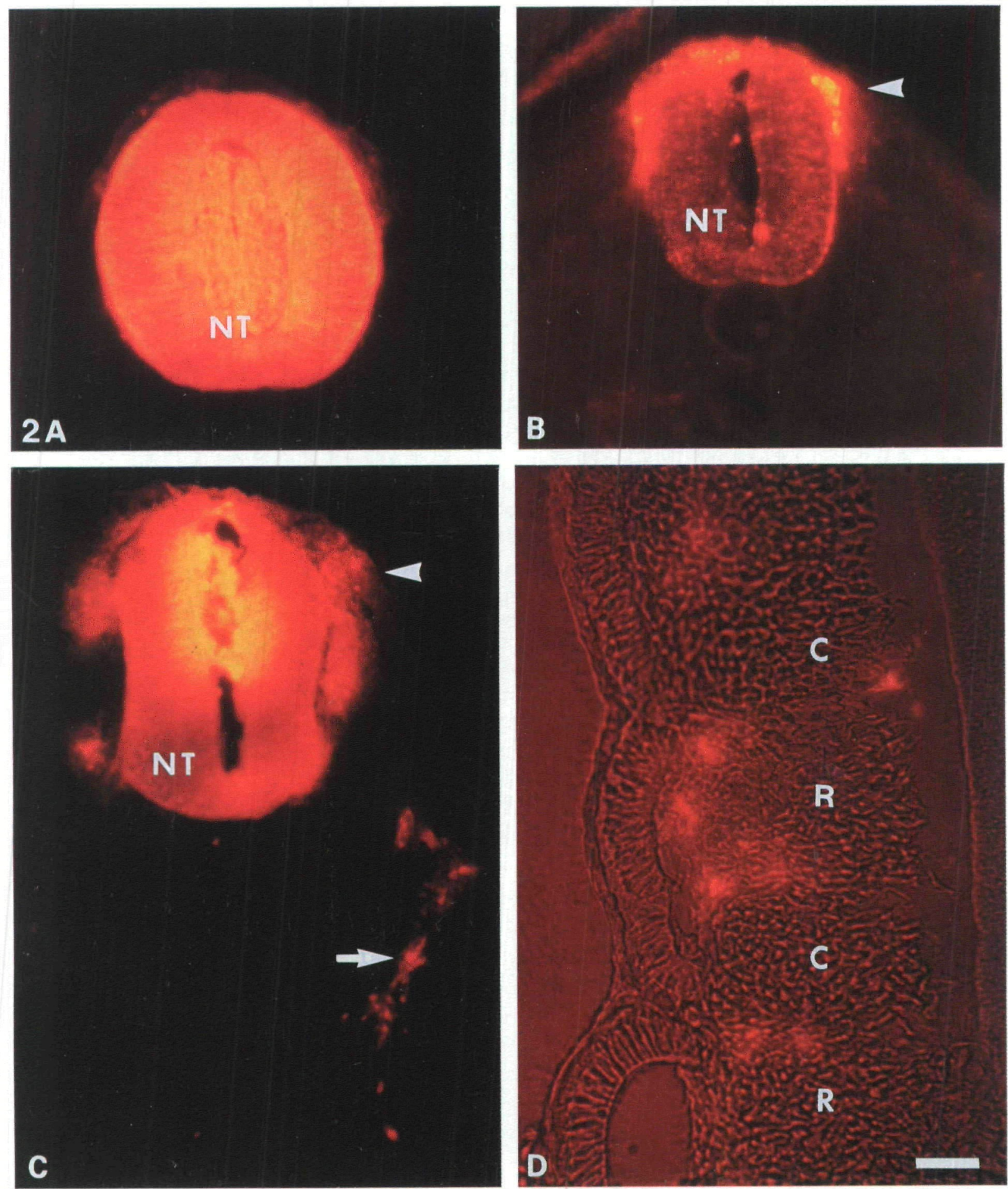

Fig. 2. Sections through embryos injected with DiI at stage 12 and incubated for an additional 4,12 or $24 \mathrm{~h}$. (A) Transverse section through an embryo fixed after $4 \mathrm{~h}$; DiI-labelled cells were seen exclusively in the neural tube (NT). (B) Transverse section through an embryo fixed after $12 \mathrm{~h}$; migrating cells were labelled with DiI (arrowhead). (C) Transverse section through an embryo fixed after $24 \mathrm{~h}$; DiI-labelled cells were observed in the sympathetic ganglia (arrow) and in the region of presumptive dorsal root ganglia (arrowhead). (D) Longitudinal section through an embryo fixed after $24 \mathrm{~h}$; DiI-labelled cells were observed in the rostral (R) half, but not the caudal (C) half, of each somitic sclerotome. (A,D: scale bar $=50 \mu \mathrm{m} ; \mathrm{B}, \mathrm{C}$ : scale bar $=125 \mu \mathrm{m})$. 

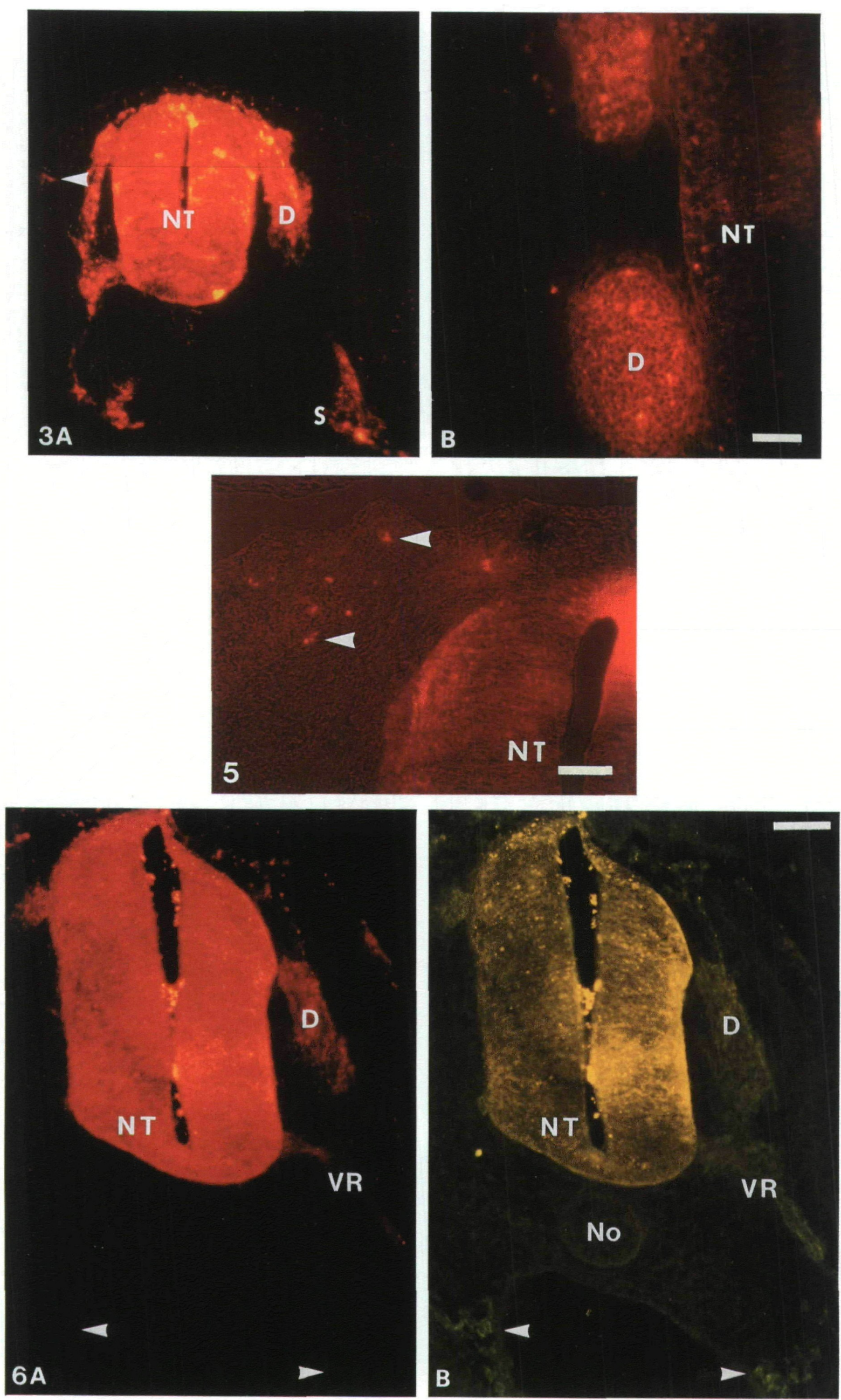
Fig. 3. Sections through embryos injected at stage 12 and incubated for an additional $48 \mathrm{~h}$. (A) Transverse sections showing DiI-labelled cells along the dorsolateral pathway (arrowhead), in the dorsal root ganglia (D), and in the sympathetic ganglia (S). (B) Longitudinal section showing DiI-labelled cells in the dorsal root ganglia (D). (A: scale bar $=125 \mu \mathrm{m} ;$ B: scale bar $=50 \mu \mathrm{m})$.

Fig. 5. A transverse section of an embryo injected with $\mathrm{DiI}$ at stage 21 and fixed at stage 23 showing Dil-labelled cells along the dorsolateral pathway. DiI-labelled cells can be seen on both the medial and lateral sides of the dermamyotome (arrowheads). (Scale bar $=20 \mu \mathrm{m}$ ).

Fig. 6. Comparison of DiI and HNK-1 labelling. Transverse section through an embryo injected with DiI at stage 17, incubated an additional $24 \mathrm{~h}$, and then fixed and stained with the HNK-1 antibody. (A) DiI-labelled cells were observed along the dorsal-lateral pathway, in the dorsal root ganglia, in the ventral root motor axons, and in the neural tube. However, DiI-labelled cells were not observed in the sympathetic ganglia (arrowheads). (B) HNK-1 immunoreactive cells are observed in the dorsal root ganglia, in the ventral root motor axons, and in the neural tube. In addition, HNK-1 immunoreactive cells also were observed in the sympathetic ganglia (arrowheads). The bright gold fluorescence in B is due to the broad fluorescent emission spectrum of DiI 'bleeding through' the fluorescein filter set. As a result, in brightly labelled sections, it is not possible to determine if DiI-labelled cells are also labelled with HNK-1. D, dorsal root ganglia; NT, neural tube; No, notochord (scale bar $=125 \mu \mathrm{m})$.

cells that migrate through the sclerotome, cells along the dorsolateral pathway did not appear to be restricted to the rostral portion of the somite. This may suggest that the rostrocaudal differences within the somitic sclerotome do not extend to the dermamyotome.

\section{Injections at progressive stages of neural crest migration}

DiI was injected at the same axial level in a series of progressively older embryos in order to determine: (1) the range of derivatives generated by neural crest cells withdrawing their endfeet from the lumen of the neural tube at later developmental times; and (2) the duration of neural crest cell emigration from the neural tube. Small injections (spreading 4-5 segments) were made at the level of the 17-18th somite at the stages indicated. The embryos were incubated until stage 23 , by which time the neural crest derivatives have formed (Lallier \& Bronner-Fraser, 1988) and were analyzed at the level of the wing bud (somites 14-16).

\section{Embryos injected at stage 12 (16 somites)}

In transverse sections, clusters of DiI-labelled cells were found in all truncal neural crest derivatives: around the dorsal aorta, in the sympathetic ganglia, in the dorsal root ganglia, and in the ventral root axons. These animals also contained single labelled cells in and around the dermamyotome and under the epidermis (Fig. 4).

\section{Embryos injected at stage 17 (29 somites)}

Individual DiI-labelled cells were located in all the same regions as those observed in embryos injected at stage 12 . However, there were fewer labelled cells around the dorsal aorta and in the sympathetic ganglia than contained in comparable regions of embryos injected at stage 12 (Fig. 4).

\section{Embryos injected at stage 19 (37 somites)}

DiI-labelled cells were found in the dorsal root ganglia, the ventral root fibers, under the epidermis, and in and around the dermamyotome (Fig. 4). In contrast to embryos injected at earlier stages, Dil-labelled cells were not found in the most ventral locations, such as around the dorsal aorta or in the sympathetic ganglia.

\section{Embryos injected at stage 21 (43 somites)}

DiI-labelled cells were almost exclusively located along the dorsolateral pathway (Figs 4 and 5). A few of the embryos also contained a small number of DiI-labelled cells in the dorsal portion of the dorsal root ganglia.

\section{Embryos injected at stage 22}

At the level of the wing bud (somites 14-16), DiIlabelled cells were found only in the neural tube.

\section{Comparison of Dil and HNK-1 labelling}

To confirm that DiI was labelling neural crest cells, sections from DiI-labelled embryos were stained with the HNK-1 antibody, which is known to label most avian neural crest cells and their derivatives (Tucker et al. 1984; Vincent \& Thiery, 1984; Bronner-Fraser, 1986). Embryos were injected with DiI at stages 12,17 or 21 , and incubated an additional $24 \mathrm{~h}$. Embryos were then fixed, sectioned and stained with the HNK-1 antibody.

As described previously, Dil-labelled cells in embryos injected at stage 12-13 were located in all neural crest derivatives. HNK-1 immunoreactive cells had a similar distribution pattern, but not all DiI-labelled cells were HNK-1 immunoreactive. For example, DiIlabelled cells that lacked HNK-1 immunoreactivity were observed under the epidermis and around the dermamyotome. In addition, not all of the HNK-1 immunoreactive cells in the dorsal root and sympathetic ganglia were labelled with DiI.

In embryos injected at the later stages, DiI was only observed in the dorsalmost derivatives, as described. In contrast, HNK-1 immunoreactivity was observed in all neural crest derivatives, with the exception of presumptive pigment cells (Fig. 6). This indicates that the absence of DiI-labelled cells in these structures is not the result of progressively later injections killing the more ventral neural crest cells.

\section{Dlscussion}

The experiments described above use the vital dye, DiI, to label premigratory neural crest cells in vivo by injecting the dye into the lumen of the neural tube. By controlling the position and the timing of the injection, it is possible to determine both the pathways and 

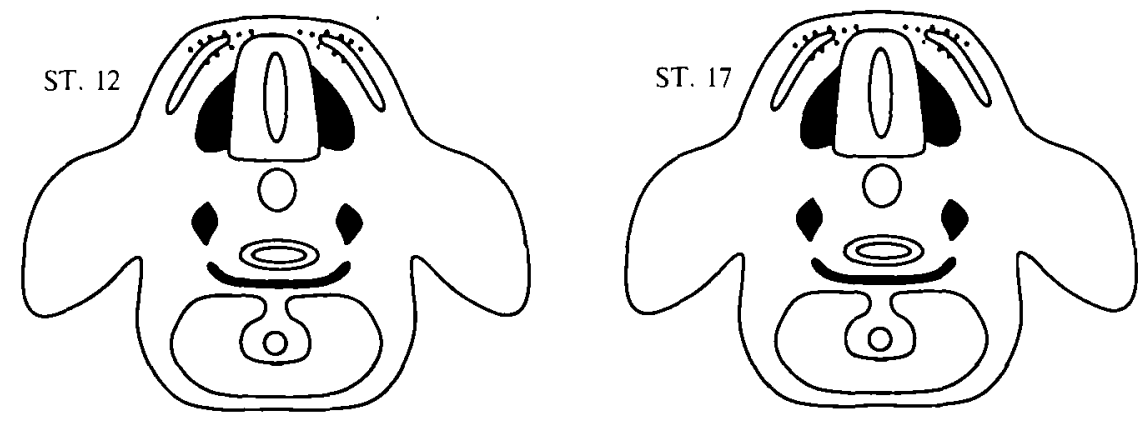

Heavy labeling in $>90 \%$ of embryos analyzed
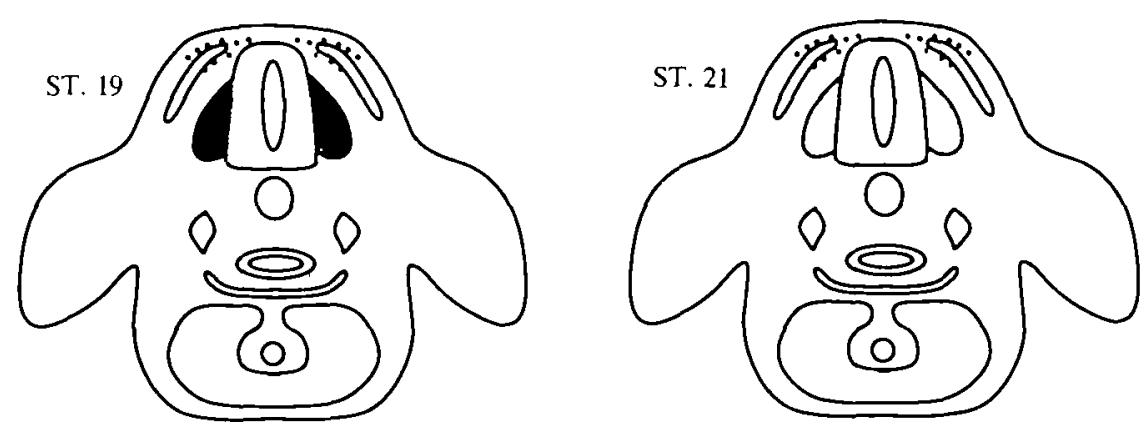

Light labeling in $>80 \%$

of embryos analyzed

Light labeling in $<10 \%$

of embryos analyzed

No label present

Fig. 4. A schematic representation of the distribution of DiI in embryos injected at the stages indicated and fixed at stage 23. Embryos injected at stage 12 contained DiI-labelled cells along the dorsolateral pathway, in the dorsal root ganglia, in the sympathetic ganglia, and around the dorsal aorta. Embryos injected at stage 17 contained Dil-labelled cells in all of the above derivatives. However, the sympathetic ganglia and the area around the dorsal aorta contained fewer DiI-labelled cells compared to the same region in embryos injected at stage 12. Embryos injected at stage 19 contained DiI-labelled cells along the dorsolateral pathway and in the dorsal root ganglia. In embryos injected at stage 21 , only the dorsolateral pathway had Dil-labelled cells. The lack of DiI labelling in the more ventral derivatives in those animals injected at a later stage indicates that these derivatives are populated by neural crest cells that withdraw their endfeet from the lumen of the neural tube before the injection.

duration of neural crest cell migration. Our results confirm and extend previous findings from transplantation and antibody labelling experiments. Neural crest cells were found to migrate along two predominant pathways: (1) a ventral pathway through the rostral portion of the sclerotome (originally described by Rickman et al. 1985); and (2) a dorsolateral pathway in and around the dermamyotome and under the epidermis. In addition, we observed some labelled neural crest cells both between adjacent somites and between the dorsal neural tube and caudal sclerotome, but not within the caudal sclerotome.

The DiI labelling technique permits a more accurate image of the dorsolateral pathway than previously possible. Based on their location and their lack of HNK-1 immunoreactivity, the cells along the dorsolateral pathway are likely to be presumptive pigment cells. DiI-labelled cells first appeared on the dorsolateral pathway at the level of the 15th somite at stage 21 . These results derived from direct cell labelling in situ are consistent with early experiments in which epidermal tissue was grafted from pigmented to nonpigmented animals (Willier \& Rawles, 1940; Rawles, 1947) or epidermis was grown in culture (Eastlick, 1939; Fox, 1949). In both of the latter approaches, melanocytes differentiated in epidermis derived from embryos after 69 to $80 \mathrm{~h}$ of incubation (stages 19-22). In contrast to the cells migrating along the ventral pathway, those migrating along the dorsal pathway show no metameric organization. We observed DiI-labelled cells on both the dorsal and ventral surfaces of the dermamyotome, consistent with a previous observation that streams of neural crest cells bifurcate at the dorsal edge of the dermamyotome (Ris, 1941). Interestingly, we observed labelled cells intercalated within the dermamyotome. On occasion, HNK-1 immunoreactive cells with similar morphologies have been seen in this location (BronnerFraser, unpublished observation). Previous studies have been unable to analyze these cells in detail because they are weakly immunoreactive for HNK-1 and because they are generally found isolated from other neural crest cells. Furthermore, because changes in cellular arrangement have been shown to block melanoblast migration (Rawles, 1940; Ris, 1941; Watterson, 1942), these presumptive melanocytes may fail to migrate after neural tube transplantation.

By injecting the DiI at progressively later stages of development, the neural crest cells were observed to populate their derivatives in a ventral-to-dorsal order. Such a progression was first suggested by experiments in which tritiated-thymidine-labelled neural tubes were transplanted from young avian embryos to older hosts (Weston \& Butler, 1966). Neural crest cells emigrating from neural tubes transplanted to embryos at the initial 
stages of emigration contributed to all derivatives. In contrast, neural crest cells emerging from neural tubes transplanted to embryos at advanced stages contributed only to dorsal derivatives. A major difficulty of grafting into progressively older embryos is the increasing trauma of the operation and the poor survival rate. In fact, Weston and Butler point out that very few of their preparations met their own criteria for acceptability (Weston \& Butler, 1966). Furthermore, their analysis was restricted to heterochronic grafts; therefore, it might not reflect the distribution that would have resulted had neural tubes of the same age been grafted between older embryos. Thus, an advantage of the DiI technique over previous efforts is that the stage-dependent differences in the distribution of the labelled cells cannot be attributed to heterochronic grafts or to agedependent healing differences. The ventral-to-dorsal order in which neural crest sites are occupied may result from a simple scheme in which neural crest cells migrate into any available space. Neural crest cells emerging later in development may be prevented from migrating into ventral regions by the neural crest cells that arrived earlier. Alternatively, this progression may result from the environment becoming nonpermissive for cell migration in a ventral-to-dorsal sequence.

Previous studies have addressed the time of onset of neural crest cell migration from the neural tube, but have been incapable of determining its duration. Experiments using either the HNK-1 antibody (BronnerFraser, 1986) or neural tube transplantation (Weston \& Butler, 1966) have shown that neural crest cells begin emigration approximately 3 somites rostral to the most recently formed somite. The duration of neural crest cell emigration can be assayed directly by performing DiI injections into progressively older embryos. Embryos injected after stage 22 no longer contained labelled cells outside of the neural tube (at the level of the wing bud). This suggests that neural crest cell emigration ceases approximately $40 \mathrm{~h}$ after initiation of migration, or 30 somites rostral to the most recently formed somite. This approach slightly overestimates the duration of emigration, because neural crest cells can migrate rostrally and caudally for short distances from their level of origin (Teillet et al. 1987). This migration of labelled cells from 'younger' caudal regions to 'older' rostral levels would result in, at worst, a three hour overestimation.

DiI has several advantages as a label for neural crest cells in vivo. Unlike some other vital dyes, DiI is not transferred from labelled to unlabelled cells. The dye does not appear to disrupt the normal pattern of migration or differentiation of neural crest cells in situ and can be observed in neural-crest-derived cells for long periods of time, suggesting it has no adverse effects on cell survival (Honig \& Hume, 1986). Furthermore, the application of the dye is relatively noninvasive, since no surgical transplantation is required. The DiIlabelling technique allows analysis of endogenous cells, rather than cells from another embryo or species, which may cause host/donor incompatibility. Because the DiI labels only those cells contacting the neural tube lumen,
DiI injections into progressively older neural tubes can be used to identify any changes in the contribution of emigrating neural crest cells to their derivatives.

As is true of other techniques, DiI labelling also has inherent flaws. First, not every neural crest cell is labelled with DiI, although DiI-labelled cells were identified in all neural crest-derived structures. This may result from the presence of a small number of the neural tube cells whose endfeet are not in contact with the lumen of the tube at the time of DiI injection, as demonstrated by our previous experiments using intracellular injection of fluorescent dextran into dorsal neural tube cells (Bronner-Fraser \& Fraser, 1988). One would not expect these cells or their progeny to be labelled with DiI. Second, the dye occasionally leaks from the neural tube at the site of the injection and stains the immediately adjacent dermamyotome. Third, the ethanol carrier causes localized damage to the neural tube at the injection site. Both the leakage and damage from the injection was restricted to the immediate vicinity of the injection site, as demonstrated by the control injections. Because neither dermamyotome cells nor neural tube cells migrate rostrocaudally (Stern \& Keynes, 1987), these latter two problems can be easily circumvented by performing our analyses 1-2 somites lengths away from the injection site. Fourth, the dye tends to run after sectioning if the tissue becomes dehydrated, sits for prolonged periods of time, or is coverslipped. This is not a serious problem when the sections are viewed immediately without a coverslip, or when sections are mounted in Gel/mount.

In summary, in situ injection of DiI into the lumen of the neural tube provides a convenient and effective method for labelling premigratory neural crest cells. A timed series of DiI injections can be used to define not only the migration pathways, but also the length and sequence of the neural crest cell emigration from the neural tube. Because Dil labelling does not require grafting, interpretation of the results is not complicated by possible effects resulting from the surgical manipulation and subsequent healing. This is especially important for examining later stages of development where limitations of survival, scarring and bleeding become more severe. Our results confirm the pathways of truncal neural crest cell migration previously described by neural tube grafting experiments and HNK-1 antibody immunostaining. Because the inherent flaws in DiI labelling experiments are complementary to those of grafting and antibody labelling experiments, the results reported here validate the observations made by previous approaches. Furthermore, the use of DiI labelling in intact embryos has made it possible to directly analyze for the first time the migration of presumptive pigment cells, the duration of neural crest migration, and the order of contribution to neural crest derivatives. Previously, only indirect approaches were used to examine these issues. An additional advantage of $\mathrm{DiI}$ is that it can be observed in living tissue, and has been used to follow axonal outgrowth in other organisms (Harris et al. 1987; O'Rourke \& Fraser, 1987; Liu \& Westerfield, 1987). Thus, the DiI technique may 
offer a direct approach for following dynamic aspects of neural crest cell migration in a variety of species.

We thank Dr Andrew Lumsden for critical reading of the manuscript and Scott Burgan for excellent technical assistance. This work was supported by BNS 8608356 (SEF), HD 25138-01, a grant from the Muscular Dystrophy Association (MDA), a McKnight Scholar Award, and a gift from the Monsanto Corporation. MBF is a Sloan Foundation Fellow.

\section{References}

Baroffio, A., Dupin, E. \& Le Douarin, N. (1988). Clone-forming ability and differentiation potential of migratory neural crest cells. Proc. natn. Acad. Sci. U.S.A. 85, 5325-5329.

Bellairs, R., Ireland, G. W., Sanders, E. J. \& Stern, C. D. (1981). The behavior of embryonic chick and quail tissues in culture. J. Embyol. exp. Morph. 61, 15-33.

BronNER-Fraser, M. (1986). Analysis of neural crest cell lineage and migration. Devl Biol. 115, 44-55.

Bronner-Fraser, M. \& Fraser, S. E. (1988). Cell lineage analysis reveals multipotency of some neural crest in avian embryos. Nature, Lond. 335, 161-164.

Chibon, P. (1967). Marquage mucleare par la thymidine tritiee des derives de la crete neurales chez l'Amphibien Urodele. Pleurodeles waltlii Michah. J. Embryol. exp. Morph. 18, 395-441.

EASTLICK, H. (1939). The point of origin of melanophores in the chick embryo by means of limb bud transplantations. J. exp. Zool. 82, 131-159.

Fox, M. H. (1949). Analysis of some phases of melanoblast migration in the barred Plymouth rock embryos. Physiol. Zool. 22, 1-22.

Hamburger, V. \& Hamilton, H. L. (1951). A series of normal stages in the development of chick embryos. J. Morph. 88, $49-92$.

Harris, W. A., Holt, C. E. \& BonhoefFer, F. (1987). Retinal axons with and without their somata, growing to and arborizing in the tectum of Xenopus embryos: time-lapse videostudy of single fibres in vivo. Development 101, 123-33.

HARRISON, (1935). Heteroplastic grafting in embryology. The Harvey Lectures. 29, 116-157.

Honig, M. G. \& Hume, R. I. (1980). Fluorescent carbocyanine dyes allow living neurons of identical origin to be studied in longterm cultures. J. Cell Biol. 103, 171-187.

Horstadius, S. (1950). The Neural Crest. Oxford Univ. Press, London and New York

Kruse, J., Mailhammer, R., Wernecke, H., Faissner, A., Sommer, I., Goridis, C. \& Schachner, M. (1984). Neural cell adhesion molecules and myelin-associated glycoproten share a common carbohydrate moiety recognized by monoclonal antibodies L2 and HNK-1. Nature, Lond. 311, 153-155.

Lallier, T. E. \& Bronner-Fraser, M. (1988). A spatial and temporal analysis of dorsal root and sympathetic ganglion formation in the avian embryo. Devl Biol. 127, 99-112.

Le Douarin, N. (1982). The Neural Crest. Cambridge, UK: Cambridge University Press.

Le Douarin, N. M. (1973). A biological cell labelling technique and its use in experimental embryology. Devl Biol. 30, 217-222.
Liu, D. W. \& Westerfield, M. (1987). The formation of terminal fields by identified motoraxons in the zebrafish. Neuroscience Abstracts 13, 1421.

Lunn, E. R., Scourfield, J., Keynes, R. J. \& Stern, C. D. (1987). The neural tube origin of ventral root sheath cells in the chick embryo. Development 101, 247-254.

O'Rourke, N. A., Fox, B. E. S. \& Fraser, S. E. (1987). Changes in optic fiber morphology during development. Neuroscience Abstracts 13, 368 .

RAWLES, M. (1940). The pigment-forming potency of early chick blastoderms. Proc. natn. Acad. Sci. U.S.A. 26, 86-94.

RAwLES, M. E. (1947). Origin of pigment cells from the neural crest in the mouse embryo. Physiol. Zool. 20, 248-266.

RAwLES, M. E. (1948). Origin of melanophores and their role in development of color patterns in vertebrates. Physiol. Review 28, 383-408.

Rickmann, M., Fawcetr, J. W. \& Keynes, R. J. (1985). The migration of neural crest cells and the growth of motor axons through the rostral half of the chick somite. J. Embryol. exp. Morph. 90, 437-455.

Ris, H. (1941). An experimental study on the origin of melanophores in birds. Physiol. Zool. 14, 48-66.

Sadaghiani, B. \& Thiebaud, C. H. (1987). Neural crest development in the Xenopus laevis embryo studied by interspecific transplantation and scanning electron microscopy. Devl Biol. 124, 91-110.

Sims, P. J., WagGoner, A. S., Wary, L. H. \& Hoffman, J. F. (1974). Studies on the mechanisms by which cyanine dyes measure membrane potential in red blood cells in phosphatidylcholine vesicles. Biochemistry 13, 3315-3330.

STERN, C. D. \& KeYNES, R. J. (1987). Interactions between somite cells: The formation and maintenance of segment boundaries in the chick embryo. Development 99, 261-272.

Teillet, M. A., Kalcheim, C. \& Le Douarin, N. M. (1987) Formation of the dorsal root ganglia in the avian embryo: segmental origin and migratory behavior of the neural crest progenitor cells. Devl Biol. 120, 329-347.

Tucker, G. C., Aoyama, H., Lipinsk, M., Turz, T. \& Thiery, JP. (1984). Identical reactivity of monoclonal antibody HNK-1 and NC-1: Conservation in vertebrates on cells derived from neural primordium and on some leukocytes. Cell Diffn. 14, 223-230.

VinCENT, M. \& Thiery, J-P. (1984). A cell surface marker for neural crest and placodal cells: Further evolution in peripheral and central nervous system. Devl Biol. 103, 468-481.

WatTERSON, R. L. (1942). The morphogenesis of down feathers with special reference to the developmental history of melanophores. Physiol. Zool. 15, 234-259.

WeSTON, J. A. (1963). A radiographic analysis of the migration and localization of trunk neural crest cells in the chick. Devl Biol. 6, 279-310.

Weston, J. A. (1970). The migration and differentiation of neural crest cells. Adv. Morphog. 8, 41-114.

Weston, J. A. \& ButLeR, S. L. (1966). Temporal factors affecting localization of neural crest cells in the chicken embryo. Devl Biol. 14, 246-266.

Willier, B. H. \& Rawles, M. E. (1940). The control of feather color pattern by melanophores grafted from one embryo to another of a different breed of fowl. Physiol. Zool. 13, 177-199. 